\title{
Road Fatalities and Their Determinants in Iran: Evidence From Panel Provincial Data
}

\author{
Enayatollah Homaie Rad, ${ }^{1}$ and Maryam Tavakkoli ${ }^{1,}$ \\ ${ }^{1}$ Guilan Road Trauma Research Center, Guilan University of Medical Sciences, Rasht, IR Iran \\ "Corresponding author: Maryam Tavakkoli, Guilan Road Trauma Research Center, Guilan University of Medical Sciences, Rasht, Guilan, IR Iran. Tel: +98-2177266861, E-mail: \\ maryam.tavakkoli2012@gmail.com
}

Received 2015 February 09; Revised 2016 January 14; Accepted 2016 February 14.

\begin{abstract}
Background: Studies have shown that the number of road fatalities has been decreasing in developed regions and increasing in less and middle developed regions. Iran has one of the highest road fatalities in the world. Controlling road fatalities is vital for less and middle developed countries like Iran.

Objectives: The aim of this study was to find factors affecting road fatalities in Iran using macro provincial data.

Materials and Methods: Panel data of provinces of Iran between 2008 and 2012 were used for this study. Panel data Poisson estimator was used for estimating the model. Hausman test and Breusch-pagan test were used for finding between pooled or panel and fixed or random effects.

Results: No significant relationships were found regarding the percentage of emergency sites and percentage of cars with road fatalities. Increase in the percentage of motorcycles, rain, highways and freeways increased the risk of road fatalities. The effect of highways in road fatalities was higher than freeways. Increase in the percentage of traffic police sites and people living in urban regions decreased the risk of accident fatalities.

Conclusions: The government, ministry of health and policy makers must develop strategies for controling high levels of road fatalities in Iran.

Keywords: Accident Prevention, Cause of Death, Accidents, Motor Vehicles, Poisson Distribution, Econometric Model, Panel Data, Iran
\end{abstract}

\section{Background}

There is a general perception that roads are not safe in middle and less developed countries. Road accidents are one of the major reasons for traumas around the world (1). An increase in economic growth and development of more motorized societies, could lead to an increase in the number of road accidents. However this is not the reason for higher numbers of fatal accidents in developed countries. In these countries the government, by enacting series of regulations and promotions, has controlled the high frequency of fatal accidents (2). It is estimated that by 2020 , fatalities of road accidents will become the third leading cause of fatalities in the world (3). These estimates have shown that fatal accidents will increase in developing countries by $80 \%$ and will decrease in developed countries by $30 \%$ till $2020(4,5)$. Controlling the number of fatal accidents in these countries is vital and is amongst the major concerns that governments are faced with. Iran has one of the biggest road fatalities in the world. Data from the world health organization (WHO) has shown that Iran is in the third place regarding unsafe roads in the world (6).

Several factors affect road fatalities. First of all it is the level of development. Development has two contradictory effects on road fatality: positive effect and negative effect. Positive effect: by having a more motorized society, the likelihood of road fatality will increase. Negative effect: in a developed region, the government has more mechanisms to control the high frequencies of road fatalities. In such regions the society is more educated and is aware of the dangers of bad driving $(2,7,8)$. Also the road emergency system works efficiently and if an accident happens, it acts immediately to decrease the likelihood of fatalities (9).

Another factor, which affects road fatalities, is population density. Studies have shown that in a region with higher population density, the number of trips is more so the roads are more crowded and thus there is a higher frequency of accidents $(10,11)$. Another factor which effects road fatality is "having more rainy days". Studies have shown that an increase in the number of rainy days increases the probability of accidents (12). The number of road emergency sites is another effective factor. In a region with more emergency sites, the probability of saving injured people will increase (13). Also, the level of education influences the rate of road fatalities. People with higher levels of education pay more attention to the recommendations of traffic police and drive more safe, so are less

Copyright ( ) 2016, Kashan University of Medical Sciences. This is an open-access article distributed under the terms of the Creative Commons Attribution-NonCommercial 4.0 International License (http://creativecommons.org/licenses/by-nc/4.0/) which permits copy and redistribute the material just in noncommercial usages, provided the original work is properly cited. 
likely to have accidents (14). The type of vehicle used is another factor which affects road fatality. Studies have shown that motorcycle and bicycle crews are at a higher risk of fatality than other bigger vehicles $(15,16)$. Age, urbanization, road width, alcohol consumption and drug use are other factors affecting fatality (17-19).

\section{Objectives}

Because of the importance of road fatalities in health, the aim of this study was to estimate the determinants of road fatalities at provincial level. Despite many epidemiological studies, which have determined factors affecting road fatalities at the micro level, there are only a few studies, which used macro data to show the effective components of road fatality. In this study panel provincial data of Iran were used to find factors affecting road fatalities.

\section{Materials and Methods}

This was a descriptive analytical study. A mortality model was used to determine factors effecting accident fatality. Panel data econometrics method was used for this purpose. Provincial data of Iran between 2008 and 2013 were used in the present study. Data contained all 31 provinces of Iran. The data were collected from Iran statistical center (ISC) and Iran road maintenance and transportation organization (IRMTO) data bank. As the study used previously gathered aggregated data, validity and reliability testing was not possible. The ISC and IRMTO were responsible for validity and reliability of the data. STATASE. v 13.1 was used for estimating the model.

\subsection{Econometrics Specification and Tests}

The objective of this study was to determine factors effecting road fatalities. In doing so, the following model was considered:

Fat $_{\text {it }}=\beta_{0}+\beta_{1}$ emergit $+\beta_{2}$ high $_{\text {it }}+\beta_{3}$ free $_{\text {it }}+\beta_{4}$ motor $_{\text {it }}+\beta_{5}$ car $_{\text {it }}+\beta_{6}$ police $_{i t}+\beta_{7}$ edu $_{i t}+\beta_{8} \operatorname{rain}_{\mathrm{it}}+\beta_{9}$ income $_{\text {it }}+\sigma_{\text {it }}$

Where: "fat" was the number of road fatalities, "Emerg" was emergency sites per length (kilometers) of a road in each province, "high" was the percentage of highways, "free" was the percentage of freeways overall, "car" was the percentage of cars, "motor" was the percentage of motorbikes. "police" was traffic police sites per length (kilometers) of a road, "edu" was the literacy rate of the population of each province, rain was the average amount of rainfall in the region, "income" was annual average income of families living in urban regions. Furthermore, $\beta$ s are coefficients, $\sigma_{\text {it }}$ is the residual of the model and $i$ is the indicator for cross and $\mathrm{t}$ is the time indicator.
In the present study, panel data were used. Panel data has some advantages in comparison with time series and cross section data. Firstly, in panel data, more information can be used. This information consists of both cross and time effects and estimations are accurate. Secondly, panel data estimations usually do not have time series and cross section biases like collinearity, heteroskedasticity and etc. Thirdly, in some countries like Iran, time series or cross section macro data are not calculated enough for separate use in econometrics models, thus mixing them gives the researchers enough data and the models could be estimable.

In addition, in count data, the dependent variable (yi) takes values $0,1,2$ because $y_{i}$ is non-negative, a functional form must be chosen that produces non-negative conditional expectations. So estimating these data with ordinary least square (OLS) data may lead to bias. In count data models it is assumed that the dependent variable has poisson distribution. maximum likelihood estimator (MLE) is the solution for estimating the model. So in this study, panel data poisson estimator was used for estimating the model. Panel data models contained two main forms: fixed or random effects, and pooled or panel effects. Let us denote the model below as a count data panel model:

$E\left\{y_{i t} x_{i t}\right\}=e^{x^{\prime} t^{\beta}}$

Where $y_{i t}$ is the dependent variable (the number of road fatalities), $x_{i t}$ is the matrix of explanatory variables and $\beta$ is the matrix of coefficients. In the model, $i$ contains cross and t contains the time. Because of using MLE estimator, the form of the model is conditional. The error term of the model is calculated as below:

$\sigma_{i t}=y_{i t}-e^{x^{\prime}}{ }^{\beta}$

Where $\sigma_{\text {it }}$ is the error term of the estimated model. In addition $\sigma_{\text {it }}$ is shown below:

$\sigma_{t i}=\mu_{i}+\nu_{t}+\epsilon_{i t}$

In this equation, $\mu_{\mathrm{i}}$ is the effects of crosses, $\nu_{\mathrm{t}}$ is the effects of time and $\varepsilon_{\mathrm{it}}$ is the residuals. In this equation, $\mu_{\mathrm{i}}$ has the average of zero with a constant variance. $\mu_{\mathrm{i}}$ is not necessarily a stochastic variable. If the $\mu_{\mathrm{i}}$ has constant values in all crosses and times, the model has pooled effect; if it has constant values for times but stochastic in crosses, the model has panel fixed effect; and if it has stochastic values for both times and crosses, the model has panel random effect. Breusch-Pagan test was used to choose between random effects or pooled effects. Also Hausman test was used for selecting between fixed or random effects. 


\section{Results}

Table 1 shows panel data descriptive statistics. In Table 1, mean, standard deviation, maximum and minimum of the variables in overall results are shown. As shown in the data, the average road fatality rate in all provinces between 2008 and 2013 was 363.8441, while the maximum amount of road fatality was 1373 in Fars province in 2010 and the minimum amount was 33, which had occurred in Ilam during year 2008. Other facts about Iran provinces are also shown in Table 1.

Estimation of the model was first done with both fixed and random effects. Next the Breusch Pagan test was used for selecting between pooled or random effects. The $\chi^{2}$ statistics of this test was 5.115 with the P-value was 0.0116 . The results of this test showed that pooled effect was not an appropriate estimator for estimating the model. Next, the Hausman test was used for selecting between fixed or random effects. The $\chi^{2}$ statistics of this test was 1.46 with the P-value was 0.9934. Thus, between fixed and random effect, random effect must be estimated. The results of panel data poisson regression using random effect and fixed effect are shown in Table 2. In the first column of this tabulation, the name of each variable, in the second column the coefficients, in the third column the standard errors for random effect estimator and in the fourth and fifth column the results of coefficients and standard errors for fixed effect are shown, respectively. The selected significant level of the model was 95\%. Bayesian information criterion (BIC) and Akaike information criterion (AIC) are added to show which of these models were better. These results confirmed that random effect estimator was better than fixed effect.

As shown in Table 2, the coefficients of highways and freeways were positive and significant. Therefore, in a province with a higher percentage of wider roads, the probability of fatal accidents will increase. The coefficient of highways was higher than the coefficient of freeways. Therefore, it could be indicated that the probability of having road fatalities is higher in highways in comparison with freeways. An increase in the percentage of motorcycles increased the likelihood of fatal accidents as well. The results of the poisson model also showed that if the number of police stations increased, the probability of having road fatalities would decrease. In addition, in provinces with more annual rain, and higher family income and literate population, the numbers of road fatalities were higher. Also, in more urbanized provinces, the number of road fatalities were less. The results of this study did not find any significant relationship between the number of road emergency sites and road fatalities. Also the percentage of cars had no significant effect on road fatalities. The final esti- mated model with the coefficients was as below:

Fat $_{\text {it }}=0.081286+1.329411$ emerg $_{\text {it }}+1.268247$ high $_{\text {it }}$ $+0^{0.565516 f_{r e e}}+2.201638$ motor $_{\text {it }}+1.731758$ car $_{\text {it }}$ 38.5154 police $_{\text {it }}+0.034462 \mathrm{edu}_{\mathrm{it}}+0.001116$ rain $_{\mathrm{it}}+9.36^{*}$ 10 -9income it $+\sigma_{\text {it }}$

Akaike's information criterion of the model was 389.5371 with 12 degrees of freedom. Bayesian Information Criterion (BIC) of the model was 407.379. Likelihood ratio test results was 2673.20 with the P-value was 0.000. Furthermore, log likelihood was -378.18967. Log likelihood ratio test shows the goodness of the estimated model for comparing with other models. Log likelihood of a model without explanatory variables was -4853.1319 . Therefore, the McFadden's $\mathrm{R}^{2}$ of the model was 0.922 , which showed the goodness of fit of the model.

\section{Discussion}

The number of road emergency sites did not change the probability of road fatalities. This indicated that, the health system of Iran did not work efficiently and could not rescue injured people. The number of road emergency sites were not sufficient enough to rescue injured people and the road emergency system was not equipped with modern vehicles like helicopters and the time of accessibility to emergency services was not $\operatorname{good}(20,21)$. The probability of fatalities leading to death was higher in highways than freeways. Freeways are designed to be safer than highways. Freeways do not have any property accesses and intersections. Constructing new freeways could help decrease the high levels of road fatalities $(22,23)$. In Iran, roads speed limit is higher for highways than regular roads. In addition, many black spots also remain in highways, which must be removed (24). Using more equipment and traffic signs are vital in the country (25). Speed cameras are very important to control speeding $(26,27)$.

By increasing the percentage of using motorcycles, the probability of road fatalities also increased. Motorcycle drivers, pedestrians and cyclists and their passengers are known as "vulnerable road users" (28). Despite stricter traffic laws of Iran for cars, buses and Lorries, there is some neglect in the implementation of laws for motorcycles. A large number of motorcycle drivers do not use helmets and the police have zoomed on car drivers only (29). The traffic fines on the violations of motorcycle drivers are not high enough to prevent them from the violations (30). The coefficient of police sites indicated the important role of police in decreasing the probability of fatal accidents. By increasing traffic regulations and improving their supervision, the number of road fatalities will decrease (31). In provinces with more rainfall, the likelihood of having road fatalities increased. Roads are wet and slippery on rainy 
Table 1. Descriptive Statistics ${ }^{\mathrm{a}}$

\begin{tabular}{|c|c|c|c|c|}
\hline Variable & Average & Standard Deviation & Minimum & Maximum \\
\hline Road fatalities & 363.8441 & 233.0023 & 33 & 1373 \\
\hline Emergency sites & 45.57527 & 26.41329 & 13 & 130 \\
\hline Freeways, km & 63.50376 & 92.0986 & 0 & 399 \\
\hline Highways, km & 359.3387 & 327.2901 & 14 & 1634 \\
\hline Police sites & 7.231183 & 3.300335 & 3 & 16 \\
\hline Cars & 34050.65 & 52284.07 & 2728 & 344798 \\
\hline motorcycles & 21191.94 & 28349.84 & 235 & 226258 \\
\hline Overall vehicles & 63263.54 & 89886.36 & 4557 & 608731 \\
\hline Income & $8.59^{*} 10^{07}$ & $4.08^{*} 10^{07}$ & 38151.41 & $2.06^{*} 10^{08}$ \\
\hline
\end{tabular}

a *Significant in $\% 5$

Table 2. The Results of Panel Poisson Regression Using Random Effect Estimator ${ }^{\mathrm{a}}$

\begin{tabular}{|c|c|c|c|c|c|}
\hline \multirow[t]{2}{*}{ Variable } & \multirow[t]{2}{*}{ Definition } & \multicolumn{2}{|c|}{ Random Effect } & \multicolumn{2}{|c|}{ Fixed Effect } \\
\hline & & Coefficient & Standard Error & Coefficient & Standard Error \\
\hline Emergency & Emergency sites & 1.329411 & 0.9844898 & 1.326145 & 0.9967278 \\
\hline High & Highways & $1.268247^{*}$ & 0.1334634 & $1.307283^{*}$ & 0.1511555 \\
\hline Free & Freeways & $0.565516^{*}$ & 0.1813165 & $0.8739348^{*}$ & 0.3378825 \\
\hline Motor & Motorcycles & $2.201638^{*}$ & 0.8537388 & 1.280129 & 0.9091967 \\
\hline Car & Cars & 1.731758 & 1.045675 & 0.8720854 & 1.081088 \\
\hline Police & Police stations & $-38.5154^{*}$ & 5.906021 & $-36.62416^{*}$ & 6.228702 \\
\hline Rain & Rain & $0.001116^{*}$ & 0.0001721 & $0.0012901^{*}$ & 0.000179 \\
\hline Education & Literacy rate & $0.034462^{*}$ & 0.0159291 & $0.0704856^{*}$ & 0.0182119 \\
\hline Income & Annual income & $9.36 * 10^{-9 *}$ & $7.19 * 10^{-10}$ & $8.86^{*} 10^{-09} *$ & $1.35^{*} 10^{-09}$ \\
\hline $\mathbf{B}_{\mathbf{0}}$ & Constant variable & 0.081286 & 1.396024 & - & - \\
\hline \multicolumn{2}{|c|}{ BIC } & \multicolumn{2}{|c|}{407.379} & \multicolumn{2}{|c|}{803.0812} \\
\hline \multicolumn{2}{|c|}{ AIC } & \multicolumn{2}{|c|}{389.5371} & \multicolumn{2}{|c|}{780.3793} \\
\hline \multicolumn{2}{|c|}{ Log likelihood } & \multicolumn{2}{|c|}{-378.18967} & \multicolumn{2}{|c|}{-584.76855} \\
\hline \multicolumn{2}{|c|}{ Likelihood ratio } & \multicolumn{2}{|c|}{-2673.20} & \multicolumn{2}{|c|}{ - } \\
\hline
\end{tabular}

a *Significant in $\% 5$

days. On slippery roads, drivers do not have the control of their vehicle as well as they do on dry roads. So the number of accidents increases on rainy days (12). In provinces with more rain, the government must improve supervision on the implementation of traffic laws and improve the infrastructure of roads and road emergency system (14). The percentage of literate population had a positive relationship with road fatalities. This variable could not be indicated as the level of education in provinces. This contained only the population, which are literate and did not include detail on the level of education. Because of the lack of data, we had to use this variable. Urbanization had a negative effect on the probability of fatal accidents, so if the percentage of rural population in a province increases, the probability of road fatalities would increase as well. Similar results were found in a study done by Grimm et al.; they used panel data of low and middle income countries and found that urbanization had a negative effect on number of road fatalities per 1000 individuals. In a region with more urban population, accessibility to health care services is easier (32). In addition, in a region with higher percentage of rural population, the number of motorcycles, pedestrians 
and other vulnerable road users, which use intercity roads are higher than a province with higher percentage of urban population, so the risk of having more road fatalities is higher (2). The annual average income had a positive relationship with the likelihood of road fatalities. This result confirms the positive effect discussed in the introduction (7). It is suggested for future studies to analyze factors effecting road fatalities at the macro level.

\subsection{Conclusions}

In this study, panel data were used to find factors affecting road fatalities at the macro level. Findings of this study could help policy makers and governors to find new solutions for the high amounts of road injuries and fatalities in Iran. The rule of enforcements to decrease the number of accidents is very important. The traffic police must pay more attention to motorcycle drivers and improve the implementation system for them. Also the government must improve the infrastructure of roads, especially in highways and the ministry of health must provide more emergency sites to rescue more injured people. This study had some limitations. Longitudinal data of this study included only five years. There were no more available provincial data to analyze the changes in time series. In addition literacy rate could not be as a good indicator for the level of education. Data for provincial mean years of school were not gathered at the provincial level.

\section{Footnote}

Authors' Contribution: Maryam Tavakkoli gathered the data, wrote the introduction and revised the manuscript; Enayatollah Homaie Rad analyzed the data, read the literature and wrote the other parts of the manuscript.

\section{References}

1. Hazen A, Ehiri JE. Road traffic injuries: hidden epidemic in less developed countries. J Natl Med Assoc. 2006;98(1):73-82. [PubMed: 16532982].

2. Scheiner J, Holz-Rau C. A residential location approach to traffic safety: two case studies from Germany. Accid Anal Prev. 2011;43(1):30722. doi: 10.1016/j.aap.2010.08.029. [PubMed: 21094329].

3. Wilson C, Willis C, Hendrikz JK, Le Brocque R, Bellamy $\mathrm{N}$. Speed cameras for the prevention of road traffic injuries and deaths. Cochrane Database Syst Rev. 2010(11):CD004607. doi: 10.1002/14651858.CD004607.pub4. [PubMed: 21069682].

4. Spiegel R. Community-based applications to enhance road safety. J Prev Interv Community. 2010;38(4):261-3. doi: 10.1080/10852352.2010.509016. [PubMed: 20945244].

5. Peden M. Global collaboration on road traffic injury prevention. Int $J$ Inj Contr Saf Promot. 2005;12(2):85-91. doi: 10.1080/15660970500086130. [PubMed: 16156532].

6. World Health Organization.. Saving millions of lives: decade of action for road safety 2011-2020. 2011
7. Eze UO, Kipsaina CC, Ozanne-Smith J. Fatal road traffic injuries in Ibadan, using the mortuary as a data source. Inj Prev. 2013;19(6):38792. doi: 10.1136/injuryprev-2012-040674. [PubMed: 23493146].

8. Anderson RW, Searson DJ. Use of age-period-cohort models to estimate effects of vehicle age, year of crash and year of vehicle manufacture on driver injury and fatality rates in single vehicle crashes in New South Wales, 2003-2010. Accid Anal Prev. 2015;75:202-10. doi: 10.1016/j.aap.2014.11.013. [PubMed: 25485731]

9. Dines AM, Wood DM, Galicia M, Yates CM, Heyerdahl F, Hovda KE, et al. Presentations to the Emergency Department Following Cannabis use-a Multi-Centre Case Series from Ten European Countries. J Med Toxicol. 2015;11(4):415-21. doi: 10.1007/s13181-014-0460-x. [PubMed: 25652342].

10. Mohan HM, Mullan D, McDermott F, Whelan RJ, O'Donnell C, Winter DC. Saving lives, limbs and livelihoods: considerations in restructuring a national trauma service. Ir J Med Sci. 2015;184(3):659-66. doi: 10.1007/s11845-014-1234-9. [PubMed: 25481642].

11. de Andrade L, Vissoci JR, Rodrigues CG, Finato K, Carvalho E, Pietrobon R, et al. Brazilian road traffic fatalities: a spatial and environmental analysis. PLoS One. 2014;9(1):ee87244. doi: 10.1371/journal.pone.0087244. [PubMed: 24498051].

12. Mishra B, Sinha Mishra ND, Sukhla S, Sinha A. Epidemiological study of road traffic accident cases from Western Nepal. Indian J Community Med. 2010;35(1):115-21. doi: 10.4103/0970-0218.62568. [PubMed: 20606934].

13. Barrimah I, Midhet F, Sharaf F. Epidemiology of road traffic injuries in qassim region, saudi arabia: consistency of police and health data. Int J Health Sci (Qassim). 2012;6(1):31-41. [PubMed: 23267302].

14. Mehmandar M, Soori H, Amiri M, Norouzirad R, Khabzkhoob M. Risk factors for fatal and nonfatal road crashes in iran. Iran Red Crescent Med J. 2014;16(8):ee10016. doi: 10.5812/ircmj.10016. [PubMed: 25389468].

15. Williams AF, Oesch SL, McCartt AT, Teoh ER, Sims LB. On-road allterrain vehicle (ATV) fatalities in the United States. J Safety Res. 2014;50:117-23. doi:10.1016/j.jsr.2014.05.001. [PubMed: 25142368].

16. Roehler DR, Ear C, Parker EM, Sem P, Ballesteros MF. Fatal motorcycle crashes: a growing public health problem in Cambodia. Int J Inj ContrSafPromot. 2015;22(2):165-71. doi:10.1080/17457300.2013.876050. [PubMed: 24499413].

17. Grummon AH, Heaney CA, Dellinger WA, Wilkins JR. What influences youth to operate all-terrain vehicles safely? Health Educ Res. 2014;29(3):533-46. doi: 10.1093/her/cyu016. [PubMed: 24740837].

18. Assari S, Moghani Lankarani M, Dejman M, Farnia M, Alasvand R, Sehat $\mathrm{M}$, et al. Drug Use among Iranian Drivers Involved in Fatal Car Accidents. Front Psychiatry. 2014;5:69. doi: 10.3389/fpsyt.2014.00069. [PubMed: 25221521].

19. De Boni R, von Diemen L, Duarte Pdo C, Bumaguin DB, Hilgert JB, Bozzetti MC, et al. Regional differences associated with drinking and driving in Brazil. Rev Bras Psiquiatr. 2012;34(3):306-13. [PubMed: 23429776].

20. Paravar M, Hosseinpour M, Mohammadzadeh M, Mirzadeh AS. Prehospital Care and In-hospital Mortality of Trauma Patients in Iran. Prehosp Disaster Med. 2014;29(5):473-7. doi: 10.1017/S1049023X14000879. [PubMed: 25196346].

21. Peyravi M, Ortenwal P, Djalali A, Khorram-Manesh A. An overview of shiraz emergency medical services, dispatch to treatment. Iran Red Crescent Med J. 2013;15(9):823-8. doi: 10.5812/ircmj.10982. [PubMed: 24616794].

22. Ossiander EM, Cummings P. Freeway speed limits and traffic fatalities in Washington State. Accid Anal Prev. 2002;34(1):13-8.

23. Choi S, Oh C, Kim M. Risk factors related to fatal truck crashes on Korean freeways. Traffic Inj Prev. 2014;15(1):73-80. doi: 10.1080/15389588.2013.778989. [PubMed: 24279969].

24. Jegede FJ. Spatio-temporal analysis of road traffic accidents in Oyo State, Nigeria. Accid Anal Prev. 1988;20(3):227-43. 
25. Mergia WY, Eustace D, Chimba D, Qumsiyeh M. Exploring factors contributing to injury severity at freeway merging and diverging locations in Ohio. Accid Anal Prev. 2013;55:202-10. doi: 10.1016/j.aap.2013.03.008. [PubMed: 23567212].

26. Carnis L, Blais E. An assessment of the safety effects of the French speed camera program. Accid Anal Prev. 2013;51:301-9. doi: 10.1016/j.aap.2012.11.022. [PubMed: 23298692].

27. Mamtani R, Al-Thani MH, Al-Thani AA, Sheikh JI, Lowenfels AB. Motor vehicle injuries in Qatar: time trends in a rapidly developing Middle Eastern nation. Inj Prev. 2012;18(2):130-2. doi: 10.1136/injuryprev-2011040147. [PubMed: 21994881].

28. Eid HO, Abu-Zidan FM. Pedestrian injuries-related deaths: a global evaluation. World J Surg. 2015;39(3):776-81. doi: 10.1007/s00268-0142853-z. [PubMed: 25373685].

29. Faryabi J, Rajabi M, Alirezaee S. Evaluation of the use and reasons for not using a helmet by motorcyclists admitted to the emergency ward of shahid bahonar hospital in kerman. Arch Trauma Res. 2014;3(3):ee19122. doi: 10.5812/atr.19122. [PubMed: 25599066].

30. Nichols JL, Tippetts AS, Fell JC, Eichelberger AH, Haseltine PW. The effects of primary enforcement laws and fine levels on seat belt usage in the United States. Traffic Inj Prev. 2014;15(6):640-4. doi: 10.1080/15389588.2013.857017. [PubMed: 24867574].

31. Sebego M, Naumann RB, Rudd RA, Voetsch K, Dellinger AM, Ndlovu C. The impact of alcohol and road traffic policies on crash rates in Botswana, 2004-2011: a time-series analysis. Accid Anal Prev. 2014;70:33-9. doi: 10.1016/j.aap.2014.02.017. [PubMed: 24686164].

32. Grimm M, Treibich C. Socio-economic determinants of road traffic accident fatalities in low and middle income countries. General Series. 2010;504:1-44. 